\title{
Atividades investigativas e indicadores de alfabetização científica em alunos dos anos iniciais do ensino fundamental
}

\author{
Investigative activities and indicators of scientific literacy in students from the first \\ years of elementary school
}

\author{
Andréia de Freitas Zompero* \\ Fernanda Tedeschi*
}

\section{Resumo}

Diariamente os professores são desafiados a promover um ensino que envolva os alunos como agentes transformadores do próprio conhecimento. O objetivo deste trabalho foi analisar a manifestação dos indicadores de alfabetização científica (AC) descritos por Sasseron (2008), como levantamento e teste de hipóteses, organização de dados e explicação dos resultados pelos alunos do $2^{\circ}$ ano do ensino fundamental (anos iniciais), a partir de uma sequência didática investigativa, envolvendo a educação ambiental. A aplicação das atividades investigativas foi realizada a partir de problemas desafiadores nos quais os estudantes deveriam buscar respostas e, assim, manifestar esses indicadores. A sequência investigativa, composta por problema, levantamento e teste das hipóteses, organização dos dados e conclusão, propôs atividades baseadas em Zabala (1998) e Carvalho (2013), que foram aplicadas uma vez por semana durante quatro meses. Analisando os resultados obtidos a partir dos trabalhos compostos por desenhos e/ou textos feitos pelos alunos ao final de cada atividade, foi possível observar que os participantes obtiveram êxito quanto à manifestação dos indicadores de AC e evoluíram quanto à linguagem científica, compreendendo alguns procedimentos para resolução de problemas, tendo em vista o conhecimento científico e a manifestação de indicadores de AC por meio de atividades investigativas.

Palavras-chave: Anos iniciais. Ensino de ciências. Indicadores de alfabetização científica. Metodologia investigativa.

\section{Abstract}

Each day teachers are challenged to promote a teaching that engages students so that they are participants in the wholeteaching-learning process, transforming agents of their own knowledge. The objective of this work was to analyze the manifestation of the indicators of Scientific Literacy - AC described by the author Sasseron (2008): survey and test of hypotheses, data organization and explanation, for the students of the 2nd year of elementary school - of an investigative didactic sequence, involving Environmental Education. The application of investigative activities was based on challenging problems in which students should seek answers and thus manifest these indicators. The research sequence proposed activities based on Zabala (1998) and Carvalho (2013) composed of problem, hypothesis collection and test, data organization and conclusion, applied once a week for four months. Analyzing the results obtained from the drawings and / or texts made by the students at the end of each activity, it was possible to observe that the participants were successful as regards the manifestation of the AC indicators and also evolved as regards the language of science, including some procedures for solving problems with a view to scientific knowledge and the manifestation of scientific literacy indicators through research activities.

Keywords: Elementary school. Indicators of scientific literacy. Investigative methodology. Teaching science.

Recebido em 19/11/2017 - Aprovado em 20/02/2018

http://dx.doi.org/10.5335/rep.v25i2.8178

Doutora em Ensino de Ciências pela Universidade Estadual de Londrina. Docente do curso de Ciências Biológicas e do mestrado em Metodologias para o Ensino de Linguagens e Tecnologias da Unopar. E-mail: andzomp@yahoo.com.br Mestre pelo Curso de Metodologias para o Ensino de Linguagens e Tecnologias da Unopar. E-mail: fted.2008@gmail.com 


\section{Introdução}

Os problemas ambientais estão diretamente relacionados com as transformações efetuadas pelo homem na natureza, como desmatamento, lançamento impróprio de resíduos orgânicos e tóxicos sem tratamento adequado no ambiente (não separação do lixo em reciclável e não reciclável), emissão de gases poluentes, entre outros fatos, que demandam preocupação mundial, discutidos em convenções internacionais para o meio ambiente.

Ao considerar os tratados ambientais dos quais o Brasil é signatário, houve a preocupação de incluir a educação ambiental nos documentos legais normatizadores da educação no país, tratando-a como tema transversal em ciências. A criação de leis para efetivar a construção de uma consciência ambiental tem se mostrado pouco eficaz. Talvez tenhamos que fomentar, nas escolas, a busca por um ensino que promova a alfabetização científica (AC) e proporcione uma aprendizagem relevante aos estudantes, para que contribuam na proteção e na preservação do meio ambiente, promovendo a harmonia com a vida nas cidades (BRASIL, 2000).

A AC almejada (CHASSOT, 2003; LORENZETTI; DELIZOICOV, 2001; SASSERON, 2008; SASSERON; CARVALHO, 2008, 2011) diz respeito à capacidade de as pessoas terem acesso ao conhecimento científico e utilizarem-no na solução dos problemas em várias esferas, inclusive daqueles causados pelo homem ao meio ambiente, com ações que minimizem os desequilíbrios ambientais. Além disso, relaciona-se à compreensão das pessoas sobre conceitos científicos e aspectos pertinentes à natureza da ciência.

Consideramos que as crianças, desde o seu ingresso na escola, mesmo antes de alfabetizadas, ou seja, como diz Rego, adquirirem "domínio desse sistema complexo de signos" (2012, p. 68), apresentam conhecimentos sobre os fenômenos naturais relacionados com vivência e cultura, como, por exemplo, preservação do meio ambiente, podendo desenvolver, segundo Sasseron e Carvalho, "competências comuns e utilizadas para a resolução, discussão e divulgação de problemas" (2008, p. 338) e apropriar-se dos conhecimentos científicos.

Considerando nossa experiência com ensino nos anos iniciais do ensino fundamental, percebemos uma abordagem para o ensino de ciências baseada no modelo memorístico, que pouco valoriza a atuação dos alunos e seus conhecimentos sobre o mundo natural e seus fenômenos. Assim, admitimos a necessidade de que as escolas repensem seus currículos para o ensino de ciências e busquem aprimorar suas práticas pedagógicas, no intuito de envolver mais a participação ativa dos estudantes no processo de ensino e aprendizagem.

$\mathrm{Na}$ proposta do aprendizado por investigação, os alunos passam a ter uma participação ativa na construção de seu próprio conhecimento, e o professor, papel fundamental na organização desse aprendizado, tendo o desafio, conforme Moran, 
Masetto e Behrens, de "tornar a informação significativa" (2013, p. 28). Cabe, assim, ao professor a mediação entre o conhecimento comum e o conhecimento científico, orientando os alunos a buscar informações científicas, analisá-las, problematizá-las, levantar hipótese e construir conhecimento crítico e reflexivo.

A AC é um dos principais objetivos para educação em ciências, e o ensino por investigação apresenta uma metodologia que pode proporcionar ao estudante o desenvolvimento das capacidades cognitivas almejadas no processo de AC. Sasseron (2008) desenvolveu estudos que apontam quais são os indicadores para AC, o que se espera para que os estudantes se desenvolvam no processo de escolarização, como levantar e testar hipóteses, organizar dados, explicá-los, entre outros. A proposta de ensino por investigação bastante difundida na literatura nacional e internacional visa, além de aprender conceitos, a permitir o desenvolvimento de capacidades cognitivas próprias da educação científica, viabilizando o processo de AC. Questionamos, então, quais indicadores de AC são manifestados por alunos do $2^{\mathrm{o}}$ ano do ensino fundamental ao desenvolverem atividades de investigação.

A presente pesquisa tem por objetivo analisar indicadores de AC manifestados por alunos do $2^{\mathrm{o}}$ ano do ensino fundamental (anos iniciais) referente ao tema Educação ambiental: a questão do lixo, incentivando-os a compreender os conteúdos com criticidade e relacioná-los ao seu cotidiano.

\section{Marco teórico}

Compreender os acontecimentos a sua volta, interferir positivamente no meio em que vivem, com a promoção da vida, a preservação e a reflexão sobre suas ações no auxílio à vida em sociedade e ao planeta, são alguns dos objetivos que a escola almeja na formação de seus alunos quanto à perspectiva da educação ambiental.

Alfabetizar cientificamente as crianças pode ser a resposta para se atingir esses objetivos. Em 1958, Paul Hurd, no artigo "Science Literacy: its meaning for american schools", inicia as discussões sobre a importância de a AC ser tratada nas escolas como programa educacional que vise ao futuro, instrumentalizando os alunos, a fim de que tenham capacidade para refletir e agir sobre o meio ambiente com base no conhecimento científico (HURD, 1958).

Chassot (2003) defende a AC como capacidade de homens e mulheres de fazer uma leitura global sobre o mundo, para tentar entender os seres humanos e a sua relação com o ambiente natural.

Sasseron e Carvalho (2008), no artigo "Almejando a alfabetização científica no ensino fundamental: a proposição e a procura de indicadores do processo" fazem algumas considerações acerca do termo AC, considerando a construção do conhecimento científico em ciências para atuação prática na sociedade. 
Ainda tecendo considerações sobre o significado de AC, Sasseron e Carvalho (2008) apresentam uma revisão bibliográfica, citando pontos comuns entre vários autores da literatura americana, o que propõe "Eixos Estruturantes da Alfabetização Científica" (2008, p. 335):

O primeiro dos eixos estruturantes refere-se à compreensão básica de termos, conhecimentos e conceitos científicos fundamentais e a importância deles reside na necessidade exigida em nossa sociedade de se compreender conceitos-chave como forma de poder entender até mesmo pequenas informações e situações do dia-a-dia. $\mathrm{O}$ segundo eixo preocupa-se com a compreensão da natureza da ciência e dos fatores éticos e políticos que circundam sua práti$c a$, pois, em nosso cotidiano, sempre nos defrontamos com informações e conjunto de novas circunstâncias que nos exigem reflexões e análises considerando-se o contexto antes de proceder. Deste modo, tendo em mente a forma como as investigações científicas são realizadas, podemos encontrar subsídios para o exame de problemas do dia-a-dia que envolvam conceitos científicos ou conhecimentos advindos deles. O terceiro eixo estruturante da AC compreende o entendimento das relações existentes entre ciência, tecnologia, sociedade e meio-ambiente e perpassa pelo reconhecimento de que quase todo fato da vida de alguém tem sido influenciado, de alguma maneira, pelas ciências e tecnologias. Neste sentido, mostra-se fundamental de ser trabalhado quando temos em mente o desejo de um futuro saudável e sustentável para a sociedade e o planeta (SASSERON; CARVALHO, 2008, p. 335, grifos das autoras).

Costa, Ribeiro e Zompero (2015) versam sobre o termo AC e discutem a perspectiva de vários outros autores quanto ao conceito e à abordagem da $\mathrm{AC}$ nos documentos de ensino e seus desdobramentos nos currículos escolares.

Neste trabalho, utilizamos o termo AC corroborando com as ideias apresentadas por Sasseron (2008), ao explicitar a capacidade dos alunos em se relacionar com o mundo e seus eventos, com a busca em soluções baseadas no conhecimento e nas práticas científicas.

As competências necessárias para que as crianças se alfabetizem cientificamente passam pelo desenvolvimento de suas habilidades cognitivas, pela apropriação do conhecimento científico e, de acordo com Lira e Teixeira (2011), por uma leitura crítica e reflexiva de mundo, para que possam utilizar o conhecimento adquirido de maneira positiva nos diferentes momentos de sua vida, em benefício de si próprio, da sociedade e do ambiente.

Lorenzetti e Delizoicov (2001) apresentam algumas ações pedagógicas para o desenvolvimento da $\mathrm{AC}$ com alunos dos anos iniciais do ensino fundamental, enfatizando a ideia de que alfabetizar cientificamente as crianças, mesmo antes de elas se apropriarem da linguagem escrita, pode favorecer significativamente a aprendizagem científica e a sua aplicação no cotidiano.

Sobre as capacidades cognitivas, Zoller (2001) já defendia um ensino voltado para investigação, com a finalidade de desenvolver habilidades cognitivas de alta ordem (Hocs), que, segundo o autor, são responsáveis por aprimorar o pensamento lógico, melhorar a capacidade de raciocínio, a tomada de decisão e a ação com competência científica. 
No documento americano Inquiry and the National Science Education Standards: a guide for teaching and learning (2000), do National Research Council (NRC), são descritas algumas habilidades cognitivas para educação científica, a serem desenvolvidas pelas crianças em várias idades. Há ênfase nas atividades de investigação, para estimular o raciocínio por meio de questionamentos, que devem ser respondidos com base em processos investigativos mediados pelo professor.

Para este estudo, consideramos a classificação dada pelo NRC (2000), grade $\mathrm{K}-4$, que diz respeito ao elementary school (Tabela 1), no qual os alunos ingressam com 5 ou 6 anos de idade e finalizam-no com 10 ou 11 anos. Comparando essa etapa de escolarização do sistema américa de ensino com o sistema brasileiro, identificamos correspondência com os anos iniciais do ensino fundamental.

Tabela 1 - Habilidades fundamentais necessárias para fazer investigação científica

\begin{tabular}{l|l}
\hline & - Fazer uma pergunta sobre objetos, organismos e eventos no ambiente. \\
& - Planejar e conduzir uma investigação simples. \\
Grade K-4 & - Empregar equipamentos simples e ferramentas para coletar dados e estender os sentidos. \\
& - Usar dados para construir uma explicação razoável. \\
& - Comunicar investigações e explicações.
\end{tabular}

Fonte: NRC (2000, p. 19, tradução nossa).

Já a publicação de 2012 do NRC (2012) faz considerações sobre os princípios norteadores para a construção do conhecimento científico. Conforme esse documento, "em qualquer nível de escolaridade" (NRC, 2012, p. 25), as crianças já são capazes de aprender ciências, desde que lhes sejam dadas as condições necessárias para esse fim.

No Brasil, o novo documento norteador dos currículos escolares, Base Nacional Comum Curricular (BNCC) (BRASIL, 2017), destaca que a escola deve valorizar os conhecimentos trazidos pelos alunos em relação à natureza, para a construção do conhecimento científico, explorando os conteúdos por meio de atividades investigativas, com a finalidade de desenvolver as habilidades cognitivas necessárias para a formação em AC.

Neste estudo, consideramos como princípio norteador para a construção do saber científico o fato de as crianças já serem capazes de desenvolver habilidades cognitivas pertinentes à educação científica, quando estimuladas com atividades que proporcionam sua autonomia, a expressão de suas ideias e ações que oportunizem o processo de alfabetização em questão.

Para essa finalidade, Carvalho (2013) apresenta como proposta para o ensino de ciências as sequências de ensino investigativas, definindo-as como um conjunto de aulas que, a partir de um tema do currículo, pode ser explorado pelos alunos, 
com oportunidade de exposição de suas ideias, conhecimento sobre o assunto, discussões, reflexões e a busca de soluções para a compreensão do assunto, tendo por base o conhecimento científico.

Consideramos ser imprescindível que os professores discutam, nas escolas, como as aulas de ciências estão sendo realizadas e priorizem atividades investigativas, em contraposição ao ensino por memorização, com o intuito de favorecer a formação de alunos críticos e reflexivos. Dessa maneira, como destacam Zompero e Laburú: "em busca de respostas" (2016, p. 17), na busca de soluções aos problemas ambientais e sociais.

Nesse sentido, a sequência didática elaborada para este estudo buscou contemplar os indicadores de AC para o ensino de ciências aos alunos do $2^{\mathrm{o}}$ ano do ensino fundamental (anos inicias), ao participarem de atividades investigativas, explorando o tema de educação ambiental.

\section{Procedimentos metodológicos}

Realizamos uma sequência de atividades investigativas com a exploração do tema meio ambiente, destacando a questão do lixo, sua destinação correta, as consequências ao ambiente e a saúde das pessoas, quando esse detrito não é corretamente descartado. A pesquisa em questão é qualitativa, com procedimentos descritivos e exploratórios, por analisar a construção do conhecimento científico e a manifestação de indicadores de AC pelos alunos a partir de uma sequência didática investigativa.

A sequência didática foi planejada e aplicada pelas pesquisadoras a estudantes matriculados numa turma de $2^{\circ}$ ano do ensino fundamental de uma escola pública municipal de Londrina. A sequência foi proposta com base nos critérios apresentados por Zabala (1998) e Carvalho (2013). Foram elaboradas três atividades investigativas, aplicadas a uma turma de 32 alunos, porém, para efeito de dados desta pesquisa, tomamos apenas os registros de 10 alunos, tendo em vista critérios de exclusão e inclusão. Esses critérios foram apresentados aos participantes e a seus responsáveis no termo de assentimento do menor, no termo de consentimento livre e esclarecido e no termo de autorização da escola, que foram aprovados pela Comissão de Ética em Pesquisa, por meio do Parecer no 2.156.018.

Buscamos, por meio dessa sequência didática investigativa, que os alunos manifestassem os indicadores de AC propostos por Sasseron (2008), com atividades que exploraram o tema destinação correta do lixo. Esses indicadores podem ser definidos da seguinte forma: 
O levantamento de hipóteses é o indicador da AC que aponta instantes em que são alçadas suposições acerca de certo tema. Este levantamento de hipóteses pode surgir tanto como uma afirmação quanto sob a forma de uma pergunta (atitude muito usada entre os cientistas quando se defrontam com um problema).

O teste de hipóteses trata-se das etapas em que as suposições anteriormente levantadas são colocadas à prova. Pode ocorrer tanto diante da manipulação direta de objetos quanto no nível das idéias, quando o teste é feito por meio de atividades de pensamento baseadas em conhecimentos anteriores.

A explicação surge quando se busca relacionar informações e hipóteses já levantadas. Normalmente a explicação é acompanhada de uma justificativa e de uma previsão, mas é possível encontrar explicações que não recebem estas garantias. Mostram-se, pois, explicações ainda em fase de construção que certamente receberão maior autenticidade ao longo das discussões. A organização de informações surge quando se procura preparar os dados existentes sobre o problema investigado. Este indicador pode ser encontrado durante o arranjo das informações novas ou já elencadas anteriormente e ocorre tanto no início da proposição de um tema quanto na retomada de uma questão, quando idéias são relembradas (SASSERON, 2008, p. 67-68, grifos da autora).

As atividades investigativas aplicadas pelas pesquisadoras iniciavam numa roda de conversa em que os alunos debatiam seus conhecimentos prévios sobre os assuntos, como, por exemplo, o que é educação ambiental, qual a quantidade de lixo produzido pelas pessoas, qual é o tempo de decomposição de resíduos orgânicos e inorgânicos, quando em contato com a terra, e quais as consequências do descarte de resíduos sólidos em locais inapropriados. Para a realização das atividades de investigação, os alunos foram divididos em pequenos grupos. Os trabalhos em pauta iniciavam sempre com a apresentação de um problema pelas pesquisadoras, após uma contextualização inicial, seguidos de discussão entre os estudantes de hipóteses direcionadas ao problema. A partir disso, buscavam-se dados para o confronto das hipóteses nos experimentos realizados ou ainda no conhecimento científico, por meio de consulta a textos, vídeos e debates, para organizar os dados. É importante destacarmos que somente nas duas primeiras atividades da sequência investigativa foram realizados experimentos. O confronto das hipóteses na atividade de número 3 foi realizado por meio de consulta a textos e ao vídeo exibido.

Ao finalizar cada uma das atividades, os estudantes apresentavam suas conclusões em textos e/ou desenhos, produzidos no intuito de responder aos problemas elencados em cada uma das atividades e sistematizar os conhecimentos. A seguir, são descritas as três atividades da sequência didática investigativa.

Divulgamos, nesta pesquisa, as atividades da sequência investigativa e os resultados obtidos a partir da análise dos materiais produzidos pelos alunos quanto à manifestação dos indicadores de AC. 


\section{Atividade 1: 0 lixo diário que eu produzo}

Esta atividade teve por objetivo levar o aluno a averiguar a quantidade de lixo reciclado que ele próprio produz em uma semana e permitir que refletisse a respeito. No início dessa atividade, foi promovido um debate para contextualização, em que os alunos deram sua opinião sobre educação ambiental e concluíram que uma forma de cuidar do planeta é cuidar da destinação do lixo.

Em seguida, com o intuito de estimular a manifestação dos indicadores de $\mathrm{AC}$, as pesquisadoras propuseram o seguinte problema: que quantidade de lixo eu produzo durante uma semana? Os alunos apresentaram suas hipóteses, indicando as quantidades (unidades ou quilogramas), considerando apenas o lixo produzido em suas casas; também debateram opções de como testar as hipóteses. De um consenso com a turma, chegaram à conclusão de que poderiam juntar, durante uma semana, apenas material reciclado em suas casas. Os dados foram anotados em um quadro, elaborado pelas pesquisadoras, conforme Figura 1. O quadro apresenta espaços para indicar o tipo de material e a data de registro, a fim de que o aluno anote a quantidade (unidade) produzida.

Figura 1 - Ficha para registrar a quantidade de lixo reciclável produzido em uma semana

\begin{tabular}{|c|c|c|c|c|c|c|}
\hline (2) & 1 - & ד-170017 & | & דוסמ-1 & - & דוots \\
\hline 2 & & & & & & \\
\hline$\underbrace{\infty 0}_{n=1}$ & & & & & & \\
\hline 2 & & & & & & \\
\hline
\end{tabular}

Fonte: dados da pesquisa.

Depois de uma semana, os alunos trouxeram à escola o lixo produzido para pesagem, que foi realizada pelas pesquisadoras; assim, puderam confrontar suas hipóteses com os dados registrados no quadro durante os dias da semana. Com 
o resultado do experimento, os estudantes observaram dados oficiais, obtidos do portal UOL, sobre quanto uma pessoa produz de lixo por dia. Por conseguinte, os alunos reuniram as informações levantadas, confrontaram suas hipóteses e apresentaram suas explicações sobre o problema produzindo desenhos.

\section{Atividade 2: decomposição dos materiais}

Nesta atividade, as pesquisadoras retomaram as conclusões dos alunos sobre o problema da primeira atividade. Por meio de debate orientado, os participantes perceberam que, quando não separam o lixo reciclável e não reciclável, esses detritos têm o mesmo destino, aterros sanitários ou lixões, que atingem sua capacidade rapidamente, à medida que o lixo se acumula. Por isso, há necessidade de reciclar o lixo, com a separação do material reciclável do não reciclável.

$\mathrm{Na}$ sequência da atividade, foi apresentado aos participantes o problema: o que demora mais para se decompor: o material orgânico ou o inorgânico? A partir disso os estudantes levantaram hipóteses e a forma de testá-las. A verificação aconteceu com a observação de amostras de materiais orgânicos (casca de banana e fatia de pão) e inorgânicos (papel: folhas de caderno; plástico: sacola de supermercado e rótulo de embalagem de refrigerante; metal: lata de alumínio; vidro: um vaso pequeno), depositados em garrafas PET com terra, de acordo com a Figura 2.

Figura 2 - Garrafas PET com amostras dos materiais orgânicos e inorgânicos para observação da decomposição

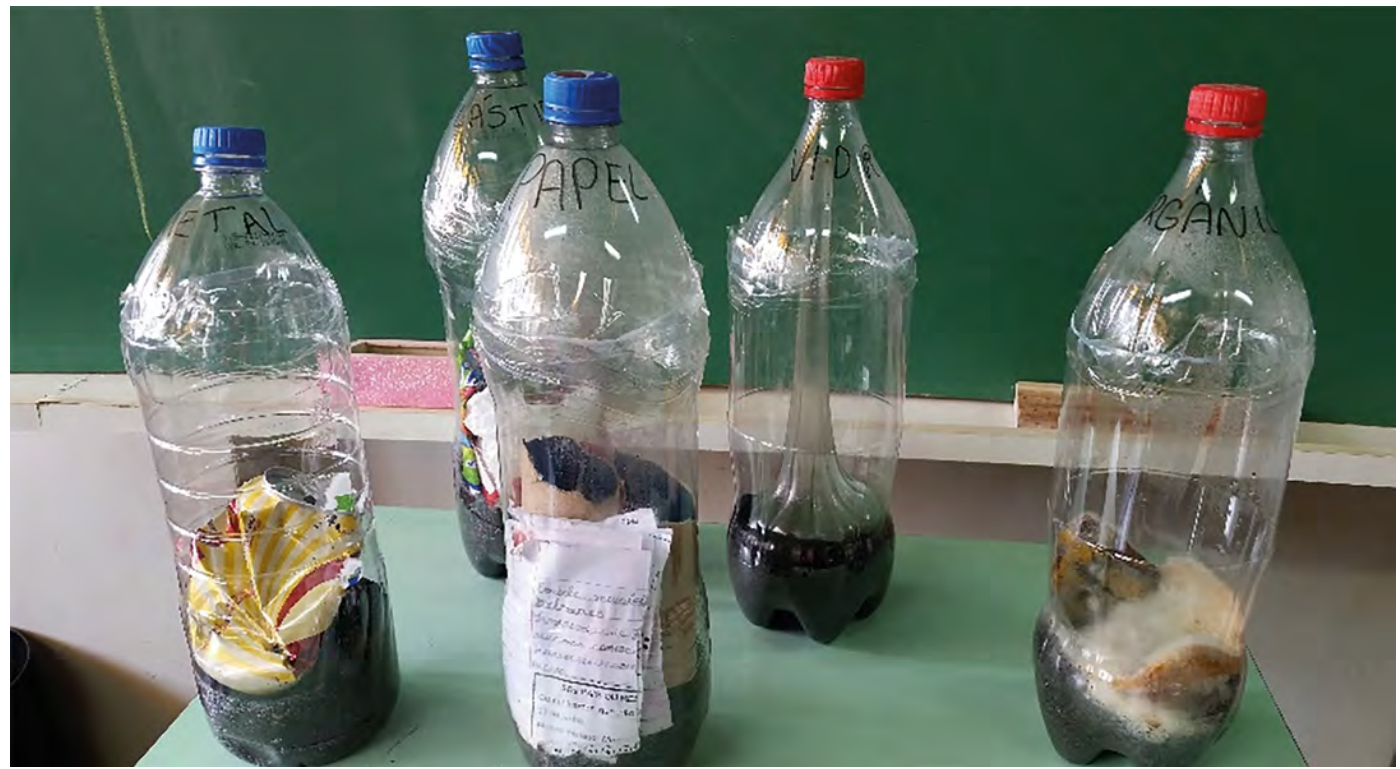

Fonte: dados da pesquisa. 
Durante quatro semanas, os alunos observaram e anotaram as alterações que ocorreram com esses materiais, em um quadro adaptado da atividade 1, conforme Figura 3.

Figura 3 - Ficha para registro do tempo de decomposição dos materiais

\begin{tabular}{|c|c|c|c|c|}
\hline MATEFLAL & 1. SEMANa & $Z$ SEMrana & 3. SEMLAR & S. SEMANa \\
\hline 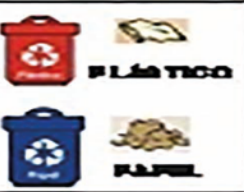 & & & & \\
\hline$\Rightarrow$ arax & & & & \\
\hline 89 & & & & \\
\hline \& 28 & & & & \\
\hline
\end{tabular}

Fonte: dados da pesquisa.

Ao final das quatro semanas, as pesquisadoras e os alunos se reuniram para analisar as observações e anotações que fizeram em relação à decomposição do lixo nos recipientes. Cada um apresentou suas anotações semanais pessoais, feitas durante o período, relatando o que era observado. Foi promovida uma roda de conversa, na qual os participantes relataram as alterações ocorridas com os materiais orgânicos e inorgânicos, o aparecimento de fungos e o cheiro.

Para o confronto das hipóteses, os estudantes compararam os dados obtidos no experimento com informações oficiais ${ }^{1}$ sobre o tempo de decomposição dos resíduos e buscaram respostas para o problema. Finalizaram essa atividade com a produção de textos individuais, registrando suas conclusões a respeito.

Atividade 3: destinação do lixo

$\mathrm{Na}$ última atividade da sequência investigativa, os participantes deveriam responder ao problema: o que pode acontecer à nossa saúde e também ao meio ambiente quando o lixo não é descartado corretamente.

Assim como nas outras atividades, os alunos levantaram hipóteses e confrontaram-nas com dados do vídeo Consequências do lixo tratado de maneira errada, que abordou a destinação do lixo. No vídeo, comentou-se sobre as implicações dos resíduos sólidos jogados em locais impróprios, o risco de doenças, os prejuízos ao 
ambiente e a necessidade de reciclar, reutilizar e reduzir o lixo produzido pelas pessoas como forma de não poluir o ar, a terra, a água; ainda abordaram-se o tempo de decomposição desses materiais recicláveis e a economia na natureza com a reciclagem. Além disso, o vídeo apresentou orientações de como as pessoas podem destinar corretamente os resíduos sólidos de suas casas.

Durante essa exibição, os estudantes fizeram registros sobre os pontos relevantes à resolução do problema. Esses registros foram sintetizados e, posteriormente, serviram de subsídio para os debates, com a finalidade de organizar os dados da pesquisa, apresentados no Quadro 1.

Quadro 1 - Síntese coletiva das informações elencadas

\begin{tabular}{|l|l|}
\hline \multicolumn{2}{|c|}{ Jogar o lixo em qualquer lugar... } \\
\hline Situação de chuva & $\begin{array}{l}\text { O lixo entope bueiros e pode causar alagamentos. } \\
\text { Se ficar água parada no lixo, cria-se o mosquito da dengue, e fica-se doente. }\end{array}$ \\
\hline Atração de insetos & $\begin{array}{l}\text { Insetos e animais que comem lixo podem transmitir doenças às pessoas. } \\
\text { Ratos podem transmitir leptospirose. } \\
\text { Moscas transportam bactérias e podem contaminar alimentos, causando doen- } \\
\text { ças, diarreia, berne, entre outros problemas. }\end{array}$ \\
\hline plásticos, vidro e papel & $\begin{array}{l}\text { Polui o ar: mau cheiro, colocar fogo, não poder respirar. } \\
\text { Polui a água, que fica imprópria para beber e pode causar a morte dos peixes. } \\
\text { Polui o solo, porque o material reciclável demora para se decompor e fica tudo } \\
\text { sujo. }\end{array}$ \\
\hline Cuidados & $\begin{array}{l}\text { Reciclar é separar o material reciclável do orgânico. } \\
\text { Reutilizar é fazer brinquedos com garrafa, CD, etc. } \\
\text { Reduzir é produzir menos lixo, fazer adubo para as plantas com restos de co- } \\
\text { mida, cascas de frutas, etc. } \\
\text { Não jogar lixo na rua é sempre colocar na lixeira para o caminhão levar. }\end{array}$ \\
\hline
\end{tabular}

Fonte: elaboração das autoras com base nas respostas dos alunos.

Os alunos finalizaram a terceira atividade produzindo desenhos e texto, registrando suas conclusões. Para finalizar a sequência investigativa, os desenhos abordaram a importância de reduzir a quantidade de lixo produzido, a necessidade de reciclar, como também a destinação correta desses materiais.

\section{Apresentação dos dados e resultados}

Iniciamos com a apresentação dos resultados dos desenhos produzidos pelos estudantes, como síntese da sequência didática investigativa. Os dados são apresentados no Quadro 2. 
Quadro 2 - Síntese das atividades da sequência investigativa

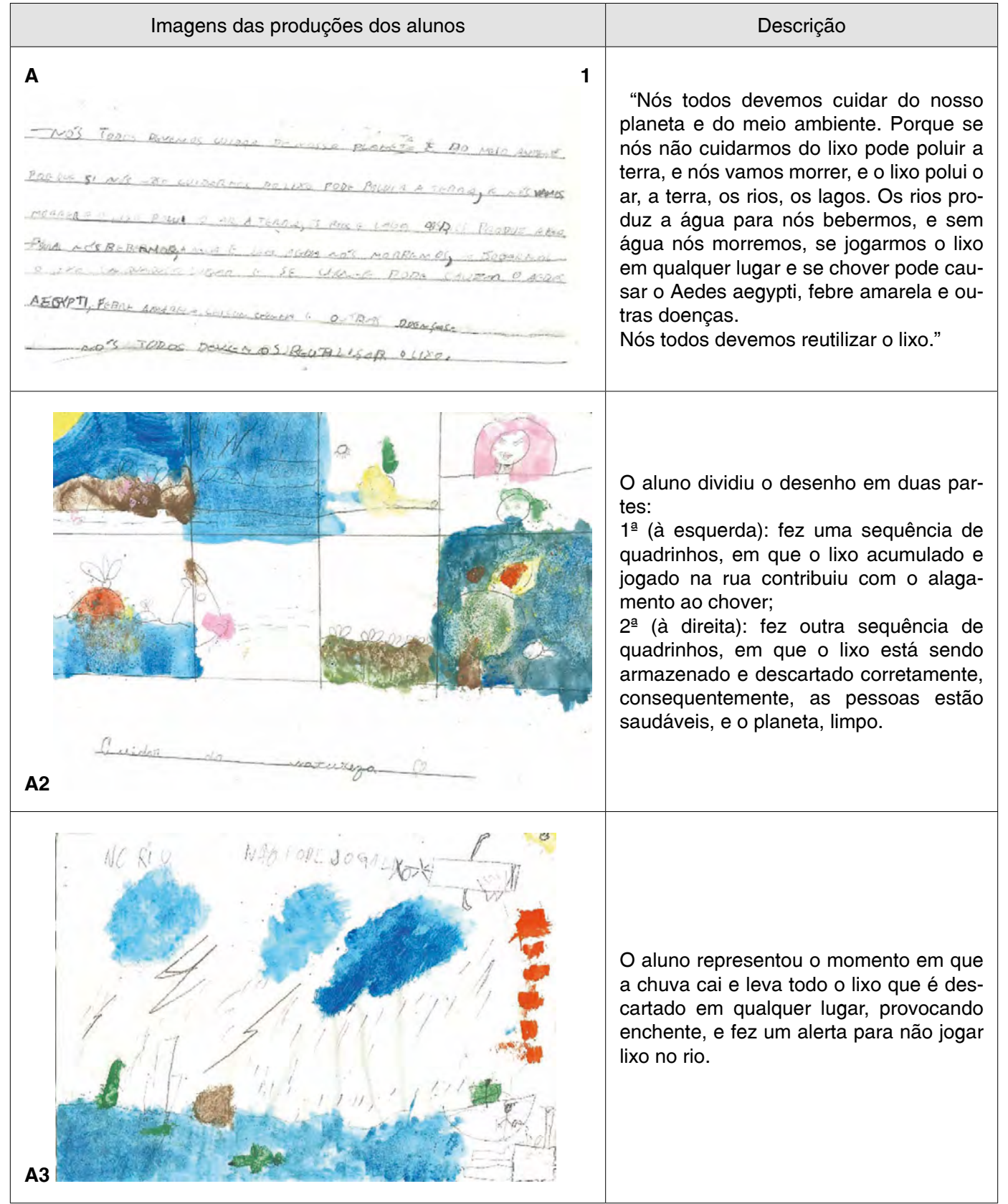




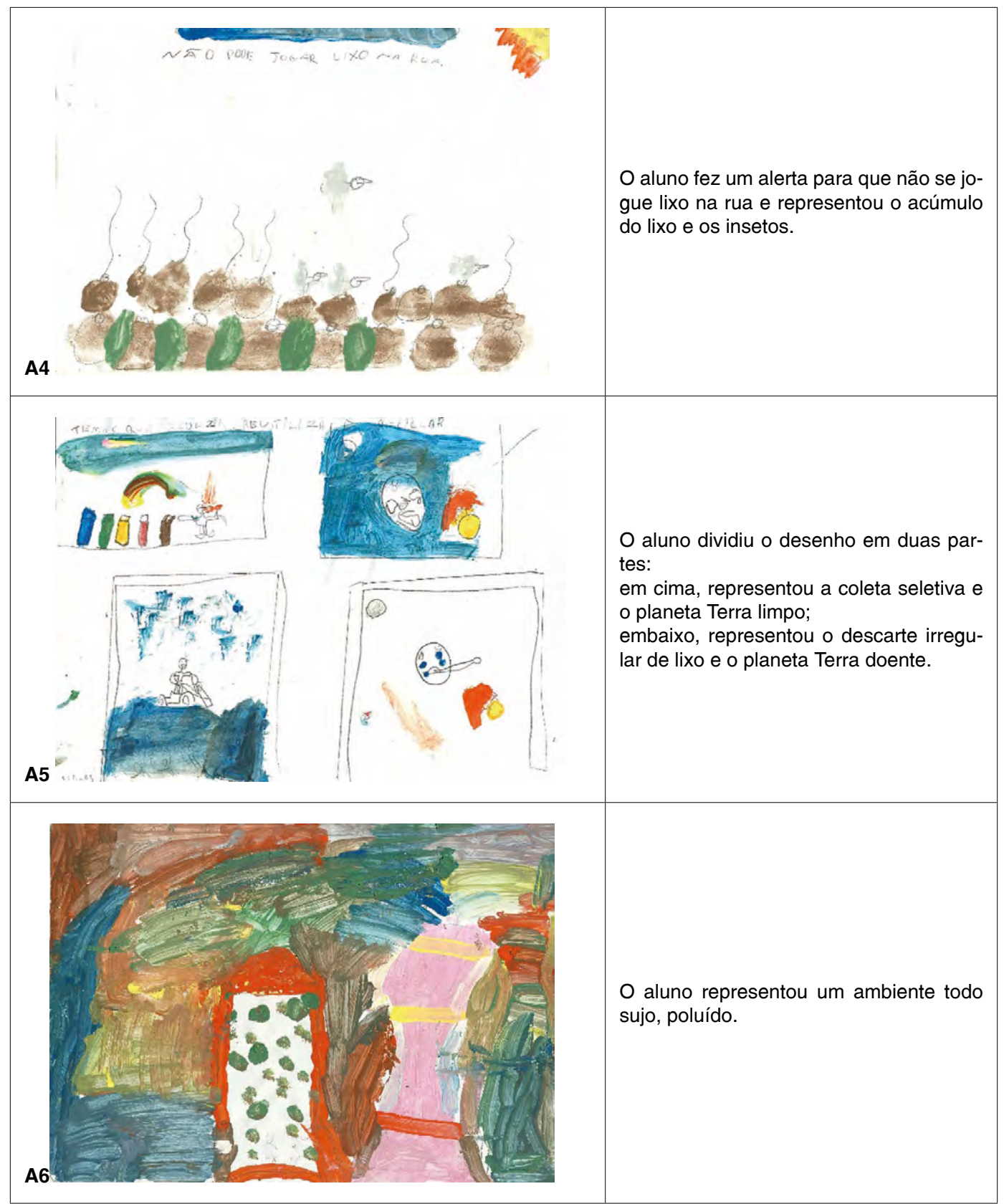




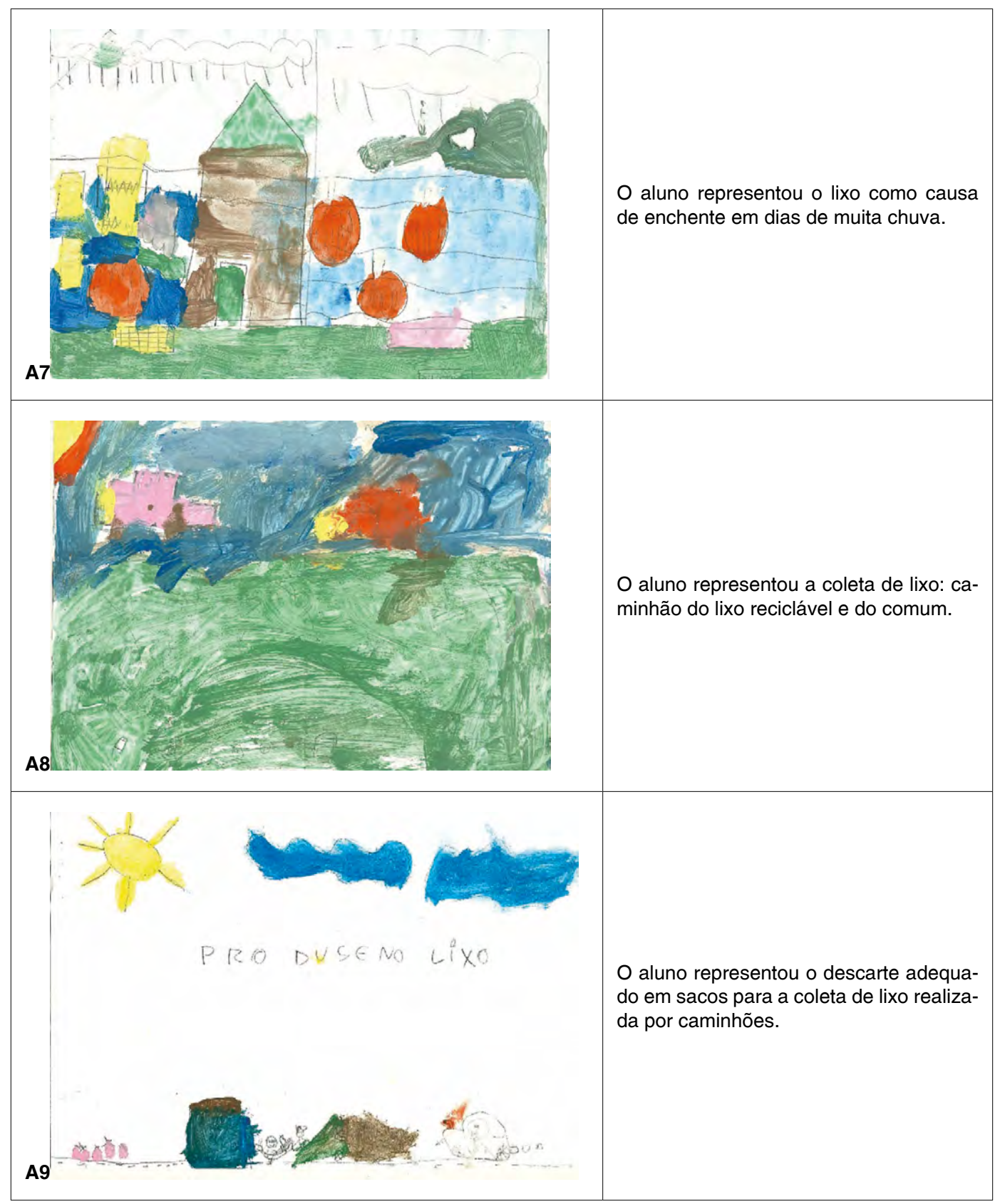




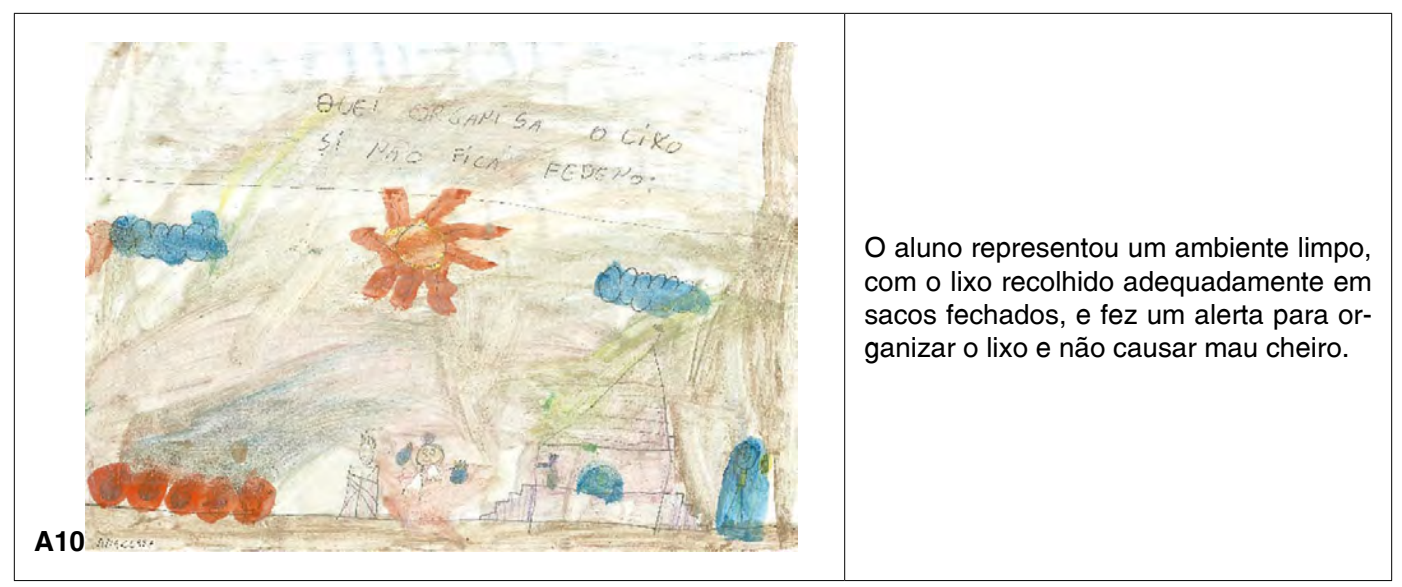

Fonte: dados da pesquisa.

Podemos observar que os participantes de A2 a A10 optaram por responder ao problema utilizando desenhos, talvez isso se deve ao fato de expressarem com maior clareza suas ideias por meio deles. Assim, solicitamos que cada aluno explicasse suas produções, com o registro de uma síntese de suas composições no Quadro 2. Apenas o aluno A1 preferiu expor suas conclusões por meio de texto. Os resultados evidenciam apenas os registros dos alunos como sistematização da sequência didática, no intuito de refletir sobre sua conduta frente às questões ambientais referentes ao descarte do lixo.

A seguir, apresentamos a análise da manifestação de indicadores de AC, propostos por Sasseron (2008), dos alunos do $2^{\circ}$ ano do ensino fundamental (anos iniciais) em cada uma das atividades.

Conforme comentado anteriormente, a sequência didática contemplou três atividades investigativas na área de ciências, nomeadas de: atividade 1, atividade 2 e atividade 3. Cada uma das atividades contemplou situações nas quais os alunos poderiam manifestar os indicadores de AC.

Para isso, foi utilizada como instrumento a tabela, na versão adaptada, de Suart e Marcondes (2009), de acordo com o Quadro 3, para analisar a manifestação dos indicadores de AC propostos por Sasseron (2008). A seguir, fazemos uma análise da síntese dos resultados obtidos nessa sequência de atividades investigativas referentes à manifestação dos indicadores pelos alunos. 
Quadro 3 - Nível de indicadores manifestados das questões propostas aos alunos

\begin{tabular}{|l|l|l|}
\hline Etapa & \multicolumn{1}{|c|}{ Indicadores } & \multicolumn{1}{c|}{ Descrição } \\
\hline E1 & $\begin{array}{l}\text { Levantamento de } \\
\text { hipóteses }\end{array}$ & $\begin{array}{l}\text { Aponta instantes em que são alçadas suposições acerca de certo tema. Po- } \\
\text { dem surgir tanto como afirmação quanto sob a forma de pergunta. }\end{array}$ \\
\hline E2 & Teste de hipóteses & $\begin{array}{l}\text { Suposições anteriormente levantadas são colocadas à prova. Podem ocorrer } \\
\text { tanto diante da manipulação direta de objetos quanto no nível das ideias. }\end{array}$ \\
\hline E3 & $\begin{array}{l}\text { Organização das } \\
\text { informações }\end{array}$ & $\begin{array}{l}\text { Acontece quando se procura preparar os dados existentes sobre o proble- } \\
\text { ma investigado. Esse indicador pode ser encontrado durante o arranjo das } \\
\text { informaç̃̃es novas ou já elencadas anteriormente, tanto no início da prepo- } \\
\text { sição de um tema quanto na retomada de uma questão, quando ideias são } \\
\text { relembradas. }\end{array}$ \\
\hline E4 & Explicação & Surge quando se busca relacionar informações e hipóteses já levantadas. \\
\hline
\end{tabular}

Fonte: adaptado de Suart e Marcondes (2009, p. 58).

Para análise dos resultados, os participantes foram identificados de A1 a A10, e as pesquisadoras, por P. No Quadro 4, podemos observar um panorama dos indicadores de AC, analisados a partir dos trabalhos desenvolvidos pelos participantes e das interações em sala de aula. Na etapa 2 da atividade 3 , a atividade para o confronto das hipóteses foi indicada pelas pesquisadoras, momento em que os alunos assistiram a um vídeo. Quanto à classificação parcial, significa que o participante manifestou parcialmente o indicador de AC em suas respostas. 
Quadro 4 - Indicadores de AC analisados na sequência didática

\begin{tabular}{|c|c|c|c|c|c|c|}
\hline Etapa & Indicadores & \multicolumn{2}{|c|}{ Descrição } & Atividade 1 & Atividade 2 & Atividade 3 \\
\hline E1 & $\begin{array}{l}\text { Levantamento } \\
\text { de hipóteses }\end{array}$ & \multicolumn{2}{|c|}{$\begin{array}{l}\text { Aponta instantes em que são al- } \\
\text { çadas suposições acerca de certo } \\
\text { tema. Podem surgir tanto como afir- } \\
\text { mação quanto sob a forma de per- } \\
\text { gunta. }\end{array}$} & $\begin{array}{l}\text { A1, } \\
\text { A2, } \\
\text { A3, } \\
\text { A } 4 \\
\text { A5, } \\
\text { A6, } \\
\text { A7, } \\
\text { A8, } \\
\text { A9, } \\
\text { A10 }\end{array}$ & $\begin{array}{l}\text { total: } A 1, \\
\text { A3, A4, A5, } \\
\text { A6, A7, A8, } \\
\text { A9, A10 } \\
\text { parcial: A2 }\end{array}$ & $\begin{array}{l}\text { A1, } \\
\text { A2, } \\
\text { A3, } \\
\text { A } 4 \\
\text { A5, } \\
\text { A6, } \\
\text { A7, } \\
\text { A8, } \\
\text { A9, } \\
\text { A10 }\end{array}$ \\
\hline \multirow[b]{2}{*}{ E2 } & \multirow[b]{2}{*}{$\begin{array}{l}\text { Teste de } \\
\text { hipóteses }\end{array}$} & \multirow{2}{*}{$\begin{array}{l}\text { Suposições ante- } \\
\text { riormente levanta- } \\
\text { das são colocadas } \\
\text { à prova. Podem } \\
\text { ocorrer tanto dian- } \\
\text { te da manipulação } \\
\text { direta de objetos } \\
\text { quanto no nível das } \\
\text { ideias. }\end{array}$} & $\begin{array}{l}\text { Sugestões } \\
\text { de atividades } \\
\text { para o expe- } \\
\text { rimento }\end{array}$ & $\begin{array}{l}\text { A1, } \\
\text { A6, } \\
\text { A7 }\end{array}$ & $\begin{array}{l}\text { A1, } \\
\text { A6, } \\
\text { A7 }\end{array}$ & $P$ \\
\hline & & & $\begin{array}{l}\text { Execução do } \\
\text { Experimento }\end{array}$ & $\begin{array}{l}\text { A1, } \\
\text { A2, } \\
\text { A3, } \\
\text { A4, } \\
\text { A5, } \\
\text { A6, } \\
\text { A7, } \\
\text { A8, } \\
\text { A9, } \\
\text { A10 }\end{array}$ & $\begin{array}{l}\text { A1, } \\
\text { A2, } \\
\text { A3, } \\
\text { A4, } \\
\text { A5, } \\
\text { A6, } \\
\text { A7, } \\
\text { A8, } \\
\text { A9, } \\
\text { A10 }\end{array}$ & $\begin{array}{l}\text { A1, } \\
\text { A2, } \\
\text { A3, } \\
\text { A4, } \\
\text { A5, } \\
\text { A6, } \\
\text { A7, } \\
\text { A8, } \\
\text { A9, } \\
\text { A10 }\end{array}$ \\
\hline E3 & $\begin{array}{l}\text { Organização } \\
\text { das informações }\end{array}$ & \multicolumn{2}{|c|}{$\begin{array}{l}\text { Acontece quando se procura pre- } \\
\text { parar os dados existentes sobre o } \\
\text { problema investigado. Esse indica- } \\
\text { dor pode ser encontrado durante o } \\
\text { arranjo das informações novas ou } \\
\text { já elencadas anteriormente, tanto } \\
\text { no início da preposição de um tema } \\
\text { quanto na retomada de uma ques- } \\
\text { tão, quando ideias são relembradas. }\end{array}$} & $\begin{array}{l}\text { A1, } \\
\text { A2, } \\
\text { A3, } \\
\text { A } \\
\text { A5, } \\
\text { A6, } \\
\text { A7, } \\
\text { A8, } \\
\text { A9, } \\
\text { A10 }\end{array}$ & $\begin{array}{l}\text { total: A1, } \\
\text { A2, A3, A4, } \\
\text { A5, A6 } \\
\text { parcial: A7, } \\
\text { A8, A9, A10 }\end{array}$ & $\begin{array}{l}\text { A1, } \\
\text { A2, } \\
\text { A3, } \\
\text { A } \\
\text { A5, } \\
\text { A6, } \\
\text { A7, } \\
\text { A8, } \\
\text { A9, } \\
\text { A10 }\end{array}$ \\
\hline
\end{tabular}

Fonte: dados da pesquisa.

Podemos observar que as atividades propostas atingiram o objeto de estimular a manifestação dos indicadores de $\mathrm{AC}$, considerando que a maioria dos alunos teve êxito nos resultados apresentados.

Com relação às atividades com os indicadores para a $\mathrm{AC}$, consideramos que os participantes demonstraram certa facilidade em executar todas as etapas, no decorrer da sequência didática, por se familiarizarem facilmente com os processos de investigação.

Destacamos que as orientações dadas aos estudantes na execução das atividades se mostraram relevantes para o sucesso deles. Nesse sentido, Carvalho (2013) 
ressalta a importância da mediação do professor nos momentos em que os alunos confrontam suas hipóteses e propõem maneiras de testá-las para a resolução do problema.

Observando a síntese dos resultados da atividade 2, percebemos que maior número de alunos tiveram dificuldade nas etapas 1 e 3 dessa atividade, ao ser comparada aos resultados das atividades 1 e 3 . Possivelmente, isso ocorreu porque a atividade 2 exigia que os alunos elaborassem ideias a partir de conhecimentos relacionados com o tempo de decomposição dos resíduos sólidos. Embora a atividade aplicada não aprofundasse os conhecimentos sobre causa e efeito, esse fator não prejudicou o intuito principal da atividade, que era a manifestação dos indicadores de AC pelos alunos.

Consideramos que levantar hipóteses é relevante, por instigar os alunos para que exponham suas ideias sobre o que entendem a respeito de determinado assunto, como afirmam García-Carmona, Criado e Cañal (2014). Também concordamos com Sasseron (2008) no que diz respeito à importância de os alunos serem estimulados a levantar hipóteses sobre uma situação-problema, apresentando ideias que poderão ser submetidas a testes e comprovações, no intuito de resolvê-la.

Ao testar as hipóteses, a etapa 2 exige dos participantes maior autonomia de suas ações, momento em que precisam colocar em prática suas habilidades para execução da tarefa. Os autores Praia, Cachapuz e Gil-Pérez (2002) afirmam que testar as hipóteses e pensar sobre os fenômenos científicos proporcionam diálogos entre os participantes, confrontando teoria e prática para a solução do problema, na tentativa de validá-las positiva ou negativamente. Temos, nesse contexto, um importante momento de interação entre professor e alunos (ZANON; FREITAS, 2007).

$\mathrm{Na}$ organização dos dados e na explicação, etapas 3 e 4, os participantes apresentaram suas conclusões nos textos e desenhos por meio de diálogo promovido em sala, com a mediação das pesquisadoras, o que produz relações com seu cotidiano e os dados pesquisados. É importante que o professor proporcione aos alunos momentos para que formulem suas ideias para a resolução do problema, registrando os dados mais relevantes e, como afirma Sasseron (2008), fundamentando cientificamente os resultados do experimento.

Por fim, ao analisar a etapa 4, podemos sugerir que metade dos participantes, isto é, 5 dos 10 alunos, obteve uma evolução quanto a sistematização dos conhecimentos adquiridos nas três atividades. Nas atividades 1 e 2 , houve a necessidade de os alunos encontrem a solução do problema a partir da proposição de um experimento. Como afirma Carvalho, para a resolução do problema: "o professor busca a participação dos alunos, levando-os a tomar consciência da ação deles. É a etapa da 
passagem da ação manipulativa à ação intelectual" (2013, p. 12). Para a realização da atividade 3, não houve necessidade de experimentação, mas, mesmo assim, os estudantes foram estimulados a manifestar os indicadores de AC. Salientamos que as atividades de investigação podem ser desenvolvidas sem experimentação.

\section{Considerações finais}

O presente estudo teve o objetivo de analisar a manifestação dos indicadores de AC apresentados por Sasseron (2008) em alunos do $2^{\circ}$ ano do ensino fundamental (anos iniciais). Para tanto, elaboramos uma sequência didática investigativa, abordando o tema Educação ambiental: a questão do lixo.

Corroboramos com Lorenzetti e Delizoicov (2001), que defendem que o processo de $\mathrm{AC}$ deve ser desenvolvido no início da escolarização, tendo em vista que, para que esse processo se efetive, há necessidade da utilização de práticas pedagógicas que incentivem a participação ativa dos alunos no processo de ensino e aprendizagem.

Dessa forma, é possível perceber, por meio dos dados apresentados nesta pesquisa, que a utilização de atividades investigativas contribuem para alcançar o objetivo proposto, por permitir a aprendizagem tanto de conceitos como de procedimentos da ciência, além de favorecer o desenvolvimento de habilidades cognitivas próprias da educação científica.

A participação e o interesse dos alunos pelas atividades da sequência investigativa foram um ponto favorável para que todos se envolvessem na situação de estudo. O NRC (2012) enfatiza a relevância do engajamento dos alunos na realização de atividades de investigação para a construção do conhecimento científico.

Vimos que a maioria dos estudantes obteve êxito quanto à manifestação dos indicadores de AC. Consideramos que as dificuldades dos alunos em alguma das etapas da sequência didática possam ter ocorrido por eles não estarem habituados a uma prática que contemple a sua participação direta na resolução de problemas.

Ao solicitar aos participantes a apresentação de suas conclusões acerca das atividades investigativas, por exemplo, com a produção de desenhos ou de textos, promoveram-se situações em que eles puderam vivenciar a apropriação da linguagem da ciência, conforme Sasseron e Carvalho (2011). As autoras consideram a aprendizagem conceitual como um dos eixos estruturantes da AC. Isso foi possível averiguar no momento em que os alunos passaram a utilizar os termos orgânico, inorgânico, decomposição e fungo em seus trabalhos ou, até mesmo, em suas falas.

Outro eixo estruturante da AC, apresentado por Sasseron e Carvalho (2011), contempla a compreensão de procedimentos em ciência para entender sua natu- 
reza. Nos momentos em que os alunos tiveram a oportunidade de participar dos processos investigativos, como, por exemplo, entendimento do problema, levantamento e teste das hipóteses, organização os dados, demonstraram entender essas práticas e, assim, desenvolverem a AC.

Foi possível perceber, no decorrer da sequência didática, que o papel mediador do professor foi fundamental, por estimular a participação dos alunos na busca por soluções, nas discussões realizadas nas rodas, e ajudá-los a refletir sobre como aplicar esse conhecimento no seu dia a dia.

\section{Agradecimento}

As autoras agradecem a Coordenação de Aperfeiçoamento de Pessoal de Nível Superior (Capes) pelo fomento à realização da pesquisa que deu origem ao presente artigo.

\section{Nota}

1 Disponível em: <http://www.lixo.com.br/content/view/146/146/>. Acesso em: 9 fev. 2017.

\section{Referências}

BRASIL. Ministério da Educação. Base nacional comum curricular: educação é a base. 2017. Disponível em: <http://cnebncc.mec.gov.br/docs/BNCC_Educacao_Infantil_e_Ensino_Fundamental. pdf>. Acesso em: 5 jul. 2017.

Secretaria de Educação Fundamental. Parâmetros curriculares nacionais: ciências naturais. Rio de Janeiro: Secretaria de Educação Fundamental, 2000.

CARVALHO, Anna Maria Pessoa. Ensino de ciências por investigação: condições para implementação em sala de aula. São Paulo: Cengage Learning, 2013.

CHASSOT, Attico. Alfabetização científica: uma possibilidade para a inclusão social. Revista Brasileira de Educação, Rio de Janeiro, v. 22, p. 89-100, jan./abr. 2003. Disponível em: <http:// www.scielo.br/scielo.php?pid=S1413-24782003000100009\&script=sci_abstract\&tlng=pt $>$. Acesso em: 8 dez. 2017.

COSTA, Washington Luiz da; RIBEIRO, Robson Fleming; ZOMPERO, Andreia de Freitas. Alfabetização científica: diferentes abordagens e alguns direcionamentos para o ensino de ciências. Unopar Científica: Ciências Humanas e Educação, Londrina, v. 16, n. 5, p. 528-532, 2015.

GARCÍA-CARMONA, Antonio; CRIADO, Ana M.; CAÑAL, Pedro. Alfabetización científica en la etapa 3-6 años: un análisis de la regulación estatal de enseñanzas mínimas. Enseñanza de Las Ciencias, Barcelona, v. 32, n. 2, p. 131-149, 2014. Disponível em: <https://www.researchgate.net/ publication/262802680_Alfabetizacion_cientifica_en_la_etapa_3-6_anos_un_analisis_de_la_regulacion_estatal_de_ensenanzas_minimas>.Acesso em: 30 dez. 2017. 
HURD, Paul Deh. Science literacy: its meaning for American schools. Educational Leadership, Washington, p. 13-16, 1958. Disponível em: <http://ascd.com/ASCD/pdf/journals/ed_lead/ el_195810_hurd.pdf>. Acesso em: 20 nov. 2017.

LIRA, Magadã; TEIXEIRA, Francimar Martins. Alfabetização científica e argumentação escrita: proposições reflexivas. In: ENCONTRO NACIONAL DE PESQUISA EM EDUCAÇÃO EM CIÊNCIAS, 8; CONGRESO IBEROAMERICANO DE INVESTIGACIÓN EN ENSEÑANZA DE LAS CIENCIAS,1, 2011, Campinas. Anais... Campinas, 2011. Disponível em: <http://www.nutes. ufrj.br/abrapec/viiienpec/resumos/R1387-1.pdf>. Acesso em: 8 fev. 2017.

LORENZETTI, Leonir; DELIZOICOV, Demétrio. Alfabetização científica no contexto das séries iniciais. Ensaio: Pesquisa em Educação e Ciências, Belo Horizonte, v. 3, n. 1, p. 1-17, 2001. Disponível em: <http://www.scielo.br/pdf/epec/v3n1/1983-2117-epec-3-01-00045.pdf>. Acesso em: 11 nov. 2017.

MORAN, José Manuel; MASETTO, Marcos T.; BEHRENS, Marilda Aparecida. Novas tecnologias e mediação pedagógica. Campinas: Papirus, 2013.

NRC. Guiding assumptions and organization of the framework. In: A framework for K-12 science education: practices, crosscutting concepts, and core ideas. Washington: NRC, 2012. p. 23-38. Disponível em: <https://www.nap.edu/read/13165/chapter/5>. Acesso em: 9 dez. 2017.

NRC. Inquiry and the national science education standards: a guide for teaching and learning. Washington: NRC, 2000. Disponível em: <https://www.nap.edu/read/9596/chapter/1\#ii>. Acesso em: 9 dez. 2017.

PRAIA, João; CACHAPUZ, António; GIL-PÉREZ, Daniel. A hipótese e a experiência científica em educação em ciência: contributos para uma reorientação epistemológica. Ciência \& Educação, Bauru, v. 8, n. 2, p. 253-262, 2002. Disponível em: <http://www.scielo.br/scielo.php?script=sci_ar ttext\&pid=S1516-73132002000200009>. Acesso em: $20 \mathrm{dez} .2017$.

SISTEMA VERDES MARES. Prefeitura de Fortaleza. Consequências do lixo tratado de maneira errada. 2014. Disponível em: <https:/www.youtube.com/watch?v=lTvv-rqqh-A>. Acesso em: 05 nov. 2017.

REGO, Teresa Cristina. Vygotsky: uma perspectiva histórico-cultural da educação. Petrópolis: Vozes, 2012.

SASSERON, Lúcia Helena. Alfabetização científica no ensino fundamental: estrutura e indicadores deste processo em sala de aula. 2008. 265 f. Tese (Doutorado em Educação) - Universidade de São Paulo, São Paulo, 2008.

SASSERON, Lúcia Helena; CARVALHO, Anna Maria Pessoa. Alfabetização científica: uma revisão bibliográfica. Investigações em Ensino de Ciências, Porto Alegre, v. 16, n. 1, p. 59-77, 2011. Disponível em: <https://www.if.ufrgs.br/cref/ojs/index.php/ienci/article/view/246/172>. Acesso em: 13 nov. 2017.

SASSERON, Lúcia Helena; CARVALHO, Anna Maria Pessoa. Almejando a alfabetização científica no ensino fundamental: a proposição e a procura de indicadores do processo. Investigação em Ensino de Ciências, Porto Alegre, v. 13, n. 3, p. 333-352, 2008. Disponível em: <https://www. if.ufrgs.br/cref/ojs/index.php/ienci/article/view/445/263>. Acesso em: $30 \mathrm{dez} .2017$. 
SUART, Rita de Cássia; MARCONDES, Maria Eunice Ribeiro. A manifestação de habilidades cognitivas em atividades experimentais investigativas no ensino médio de química. Ciências $e$ Cognição, Rio de Janeiro, v. 14, n. 1, p. 50-74, 2009. Disponível em: <http://www.cienciasecognicao.org/pdf/v14_1/m318318.pdf>. Acesso em: $29 \mathrm{dez} .2017$.

ZABALA, Antoni. A prática educativa: como ensinar. Porto Alegre: Artmed, 1998.

ZANON, Dulcimeire Aparecida Volante; FREITAS, Denise. A aula de ciências nas séries iniciais do ensino fundamental: ações que favorecem a sua aprendizagem. Ciências \& Cognição, Rio de Janeiro, v. 10, p. 93-103, 2007. Disponível em: <http://www.cdcc.usp.br/maomassa/doc/m317150. pdf>. Acesso em: 25 nov. 2017.

ZOLLER, Uri. Alternative assessment as (critical) means of facilitating HOCS-Promoting teaching and learning in chemistry education. Chemistry Education: Research and Pratice en Europe, [S. 1.], v. 2, n. 1, p. 9-17, 2001. Disponível em: <http://pubs.rsc.org/en/content/articlelanding/2001/ rp/b1rp90004h\#!divAbstract>. Acesso em: 29 dez. 2017.

ZOMPERO, Andreia de Freitas; LABURÚ, Carlos Eduardo. Atividades investigativas para as aulas de ciência: um diálogo com a teoria da aprendizagem significativa. Curitiba: Appris, 2016. 